\title{
Impact of disease stage and aetiology on survival in hepatocellular carcinoma: implications for surveillance
}

\begin{abstract}
Philip Johnson ${ }^{*}, 1,2$, Sarah Berhane ${ }^{1}$, Chiaki Kagebayashi ${ }^{3}$, Shinji Satomura ${ }^{3}$, Mabel Teng ${ }^{4}$, Richard Fox ${ }^{5}$, Winnie Yeo ${ }^{6}$, Frankie $\mathrm{Mo}^{6}$, Paul $\mathrm{Lai}^{7}$, Stephen L Chan ${ }^{6}$, Toshifumi Tada ${ }^{8}$, Hidenori Toyoda ${ }^{8}$ and

Takashi Kumada ${ }^{8}$

${ }^{1}$ Department of Molecular and Clinical Cancer Medicine, University of Liverpool and Clatterbridge Cancer Centre NHS Foundation Trust, Sherrington Building, Ashton Street, Liverpool, Merseyside L69 3GA, UK; ${ }^{2}$ The Clatterbridge Cancer Centre NHS Foundation Trust, Clatterbridge Road, Bebington, Wirral CH63 4JY, UK; ${ }^{3}$ Department of Molecular Biochemistry and Clinical Investigation, Osaka University Graduate School of Medicine, Osaka, Japan; ${ }^{4}$ Department of Oncology, Addenbrooke's Hospital, University of Cambridge, Hills Road, Cambridge CB2 0QQ, UK; ${ }^{5}$ Cancer Research UK Clinical Trials Unit, School of Cancer Sciences, University of Birmingham, Birmingham B15 2TT, UK; ${ }^{6}$ State Key Laboratory in Oncology in South China, Sir YK Pao Centre for Cancer, Department of Clinical Oncology, Chinese University of Hong Kong, Hong Kong Cancer Institute, Hong Kong, China; ${ }^{7}$ Department of Surgery, Prince of Wales Hospital, Chinese University of Hong Kong, Hong Kong, China and ${ }^{8}$ Department of Gastroenterology and Hepatology, Ogaki Municipal Hospital, 4-86 Minaminokawa-cho, Ogaki, Gifu 503-8052, Japan
\end{abstract}

Background: Variation in survival in hepatocellular carcinoma (HCC) has been attributed to different aetiologies or disease stages at presentation. While international guidelines recommend surveillance of high-risk groups to permit early diagnosis and curative treatment, the evidence that surveillance decreases disease-specific mortality is weak.

Methods: We compared HCC survival figures from Japan $(n=1174)$ and Hong Kong $(n=1675)$ over similar time periods (Japan 2000-2013, Hong Kong, China 2003-2014). The former has an intensive national surveillance programme, while the latter has none. We also analysed changes in survival in Japan over a 50-year period including data from before and after institution of a national HCC surveillance programme.

Results: In Japan, over $75 \%$ of cases are currently detected by surveillance, whereas in Hong Kong $<20 \%$ of cases are detected presymptomatically. Median survival was 52 months in Japan and 17.8 months in Hong Kong; this survival advantage persisted after allowance for lead-time bias. Sixty-two per cent of Japanese patients had early disease at diagnosis and $63 \%$ received curative treatment. The comparable figures for Hong Kong were $31.7 \%$ and $44.1 \%$, respectively. These differences could not be accounted for by disease aetiology, and patients in Hong Kong who were detected at an early stage had a similar survival to the analogous patients in Japan.

Conclusions: The variation in survival is largely accounted for by stage at diagnosis, which in turn relates to the intensity of surveillance programmes and the consequent variation in curative therapeutic options.

A striking feature of hepatocellular carcinoma (HCC) is the wide global variation in incidence, ranging from $<3 / 100000$ in Northern Europe to $>30 / 100000$ in parts of Africa and China
(Parkin et al, 2005). In all regions, most HCC arises in the setting of chronic liver disease (Llovet, 2005). Equally striking is the wide variation in reported median survival figures ranging from $<3$

*Correspondence: Professor P Johnson; E-mail: Philip.Johnson@liverpool.ac.uk 
months in parts of Africa to $>3$ years in Taiwan and Japan (Chen et al, 2006; Hsu et al, 2010).

Recognising the crucial importance of early diagnosis for the implementation of potentially curative therapy, most international guidelines suggest that patients at high HCC risk (Omata et al, 2010; Bruix and Sherman, 2011; For Research, EO and Liver, EAFTSOT, 2012; Song et al, 2012) are screened by six monthly ultrasound (US) examinations with or without the serum tumour marker $\alpha$-fetoprotein (AFP). However, systematic reviews conclude that the evidence that surveillance decreases disease-specific mortality is weak (Kansagara et al, 2014) and the US National Cancer Institute concludes that 'surveillance of persons at elevated risk does not result in a decrease in mortality from hepatocellular cancer' (NCI). The only randomised trial showing benefit from surveillance (Zhang et al, 2004) had significant methodological limitations (Kansagara et al, 2014). Furthermore, although those who are detected within a surveillance programme tend to have 'earlier' disease and survive longer, the possibility that this is attributable to lead-time bias is difficult to exclude (Singal et al, 2014; Sherman, 2014b). However, it is recognised that a formal randomised trial of surveillance to provide the relevant evidence base is now impossible, not least because properly informed patients would not consent to recruitment to a control, unscreened arm, particularly in the light of international clinical guidelines (McCaughan, 2013; Kansagara et al, 2014; Singal et al, 2014; Sherman, 2014b). On the basis of this lack of evidence, most Western countries have chosen not to implement a national surveillance programme and it has been left to individual hospitals or clinicians to undertake surveillance resulting in very variable practice (Dalton-Fitzgerald et al, 2014; Joshi et al, 2014). Thus, patients are caught between guidelines written by HCC 'experts' who strongly support surveillance and funders who are reluctant to act on these guidelines in the absence of a firm conventional evidence base, while both sides recognise that such an evidence base is impossible to acquire.

In an attempt to provide some evidence as to the potential benefits of surveillance for HCC without a formal randomised trial, we have compared HCC survival rates in two national patient cohorts both with advanced and sophisticated health-care systems. One of these, Japan, has a mature, intensive, national programme of surveillance for HCC, whereas the second, Hong Kong, has not introduced such a programme.

\section{PATIENTS AND METHODS}

The study involved patient level data from HCC centres in Japan and Hong Kong, China. Part of the Japan cohort has previously been reported by Toyoda et al (2006b), whereas the Chinese cohort comprised consecutive patients drawn from the North West Territories, Hong Kong. We also had access to historical data pertaining to changes occurring in the same region of Japan over the period between 1969 and 2013 in terms of age, survival, 90-day postoperative mortality, tumour size and stage (as assessed by the Japanese Integrated Staging (JIS) score) with which to assess the impact of the introduction of surveillance in 1980.

Diagnosis, tumour characteristics and assessment of survival. Patients were diagnosed on the basis of characteristic radiology according to international guidelines (For Research, EO and Liver, EAFTSOT, 2012) or histological examination of tumour tissue. Survival was calculated from date of diagnosis. Parameters recorded common to both cohorts are shown in Table 1. Aetiology was classified as hepatitis B virus (HBV) or hepatitis C virus (HCV) related or 'other', the latter including alcoholic and other forms of chronic liver disease (Table 1). Where aetiology was mixed, typically HCV and alcohol, the former was recorded.
Treatment and staging. Japanese patients were staged according to the JIS score (Kudo et al, 2003). In Hong Kong (China), treatment was decided in multidisciplinary meetings. Liver transplantation was not available in the Hong Kong or Japanese centres. Both units had ready access to 'state-of-the-art' treatments, which was not influenced by cost considerations. The Milan Criteria (three tumours $<3 \mathrm{~cm}$ or one tumour $<5 \mathrm{~cm}$; Mazzaferro et al, 1996) was used to classify patients as having early (potentially curative disease) or advanced disease (Singal et al, 2014). Resection, radiofrequency ablation and percutaneous ethanol injection were considered potentially curative treatments. All other treatment options were considered palliative.

Surveillance policy. Mass surveillance was introduced in Japan in 1980. The approach adopted in the Ogaki prefecture, described here, is typical of the whole of Japan (The Japan Society of Hepatology, 2010a, b; Kudo et al, 2016). The population above the age of 50 years is offered regular screening for chronic viral hepatitis. All patients with cirrhosis or severe fibrosis are followedup with US examination every 3-6 months; no patients are excluded on the grounds of advanced liver disease/liver failure. Regular monitoring of tumour markers (AFP, AFP-L3\% and desgamma-carboxy prothrombin) is also performed every 3-6 months. When an increase of tumour markers is observed, additional imaging examinations are performed. In Hong Kong, China there was no formal surveillance programme.

Statistical methods. Statistical analysis was undertaken using Stata IC 12 (Stata Corp, College Station, TX, USA). Survival curves were generated by the Kaplan-Meier method. Univariable Cox regression analysis was used to identify significant prognostic variables in each of the cohorts. Variables analysed were age, gender, albumin $\left(\mathrm{gl}^{-1}\right), \operatorname{AFP}\left(\mathrm{ng} \mathrm{ml}^{-1}\right)$, bilirubin $\left(\mu \mathrm{moll}^{-1}\right)$, treatment (curative/palliative), tumour size $(\mathrm{cm})$, tumour type (solitary or multifocal), vascular invasion, aetiology (HCV/HBV/ $\mathrm{HCV}+\mathrm{HBV}$, other) and screening status. A log transformation was made to AFP and bilirubin because of extreme skewness. To make allowance for lead-time bias introduced by systematic surveillance, we applied the method of Duffy et al (2008). Using forward selection, a multivariable Cox proportional hazards model was built to explain variation in survival as related to clinical features and aetiological factors.

\section{RESULTS}

Comparing similar time periods (Japan 2000-2013; Hong Kong, China 2003-2014), median survival in Japan was 52 months compared with 17.8 months in Hong Kong (Figure 1A). This difference in survival was maintained even after allowing for leadtime bias (Figure 1B). By all measures of disease extent and stage (tumour size $<3 \mathrm{~cm}$, multifocality, vascular invasion as well as the Milan Criteria), the Japanese cohort had much earlier disease at diagnosis (Table 2). However, within that cohort of Hong Kong patients who were detected at an early stage (i.e., within the Milan Criteria), the median survival was actually significantly better than for the analogous Japanese group (Figure 1C), although among those with good liver function (Child-Pugh grade 'A') survival figures were virtually identical (Figure 1D) as were results among those who underwent surgical resection or who were classified as receiving curative theory (data not shown). Comparing the Kaplan-Meier survival curves for late-stage patients with tumour sizes of over $5 \mathrm{~cm}$ (outside the Milan criteria) showed that there was no statistically significant difference $(P=0.2068)$ between the Japanese and Chinese patients (Supplementary Figure 1).

Changes in survival following introduction of surveillance programme in Japan. In the latest cohort (2000-2013), 78\% of 
Table 1. Characteristics of the cohorts

\begin{tabular}{|c|c|c|c|}
\hline & \multicolumn{2}{|c|}{ Japan } & Hong Kong, China \\
\hline $\mathbf{N}$ & \multicolumn{2}{|c|}{2605} & 1675 \\
\hline Accrual period & $1966-1999, n=1431$ & $2000-2013, n=1174$ & $2003-2014$ \\
\hline \% Ethnicity & $>95 \%$ (Oriental) & $>95 \%$ (Oriental) & $>95 \%$ (Oriental) \\
\hline $\begin{array}{l}\text { Age (years) } \\
\text { Median (IQR) } \\
\text { Mean ( } \pm \text { s.d.) }\end{array}$ & $\begin{array}{r}63(56,69) \\
62.6( \pm 9.5)\end{array}$ & $\begin{array}{c}70(63,76) \\
68.8( \pm 9.5)\end{array}$ & $\begin{array}{r}59(52,68) \\
59.6( \pm 11.4)\end{array}$ \\
\hline$\%$ Male & $75.8, n=1431$ & $70.8, n=1174$ & $84.6, n=1675$ \\
\hline $\begin{array}{l}\text { \% Aetiology } \\
\text { HCV } \\
\text { HBV } \\
\text { HCV + HBV } \\
\text { Other }\end{array}$ & $\begin{array}{c}n=1326 \\
48.8 \\
21.6 \\
0.9 \\
28.7\end{array}$ & $\begin{array}{c}n=1174 \\
66.4 \\
15.7 \\
0.9 \\
17\end{array}$ & $\begin{array}{c}n=1112 \\
6.7 \\
80.5 \\
0.5 \\
12.2\end{array}$ \\
\hline \multicolumn{4}{|c|}{ Liver function and cancer biomarkers } \\
\hline $\begin{array}{l}\left.\text { AFP (ng } \mathrm{ml}^{-1}\right) \text {, median (IQR) } \\
\text { Bilirubin }\left(\mu \mathrm{mol} \mathrm{I}^{-1}\right) \text {, median (IQR) } \\
\text { Albumin }\left(\mathrm{gl}^{-1}\right) \text {, median (IQR) } \\
\% \text { Child score (A: B:C) }\end{array}$ & $\begin{array}{c}68.0(14,1130), n=1216 \\
17.1(10.3,29.1), n=1404 \\
32(27,36), n=1375 \\
46.0: 39.1: 15.0, n=1429\end{array}$ & $\begin{array}{c}21.3(6.3,208.5), n=1156 \\
13.7(10.3,22.2), n=1168 \\
36(32,40), n=1168 \\
70.2: 22.5: 7.3, n=1174\end{array}$ & $\begin{array}{c}107(9,2869), n=1675 \\
15(10,26), n=1675 \\
38(34,42), n=1675 \\
75.9: 20.2: 3.9, n=1675\end{array}$ \\
\hline \multicolumn{4}{|c|}{ Tumour characteristics and disease stage } \\
\hline $\begin{array}{l}\text { \% Multifocal } \\
\text { Tumour size } \\
<3 \mathrm{~cm}(\%) \\
3-5 \mathrm{~cm}(\%) \\
5.1-10 \mathrm{~cm}(\%) \\
>10 \mathrm{~cm}(\%) \\
\% \text { Vascular invasion (presence) } \\
\% \text { HCC detected through surveillance } \\
\% \text { within the Milan Criteria } \\
\text { Treatment (\% curative) }\end{array}$ & $\begin{array}{c}67.4, n=1431 \\
n=1043 \\
44.9 \\
27.1 \\
20.9 \\
7.1 \\
42.4, n=1341 \\
59.50, n=1312 \\
35.2, n=1430 \\
29.3, n=1431\end{array}$ & $\begin{array}{c}43.8, n=1165 \\
n=1164 \\
52.8 \\
22.3 \\
18.9 \\
6 \\
16, n=1163 \\
77.60, n=1172 \\
62, n=1159 \\
62.8, n=1170\end{array}$ & $\begin{array}{c}45.4, n=1675 \\
n=1600 \\
25.3 \\
25.6 \\
25.9 \\
23.2 \\
26.7, n=1675 \\
\text { NA } \\
\text { 31.7, } n=1624 \\
44.1, n=1675\end{array}$ \\
\hline \multicolumn{4}{|l|}{ Survival } \\
\hline Median overall survival (months) & $16.6, n=1430$ & $52, n=1174$ & $17.8, n=1672$ \\
\hline
\end{tabular}

Japanese HCC cases were detected by surveillance. The high current median survival seen in Japan was preceded by increasing survival rates over several decades (Figure 1E). Thus, between the years of 1966 and 1980 when there was no surveillance programme in place, median survival in Japan was $<3$ months (Toyoda et al, 2006a). Survival improved over each following decade, from 8.8 months between 1980 and 1989 to the most recent figure of over 4 years (2000-2013; Figure 1E). The median age at diagnosis also increased each decade, from 60.5 years before the initiation of a surveillance programme to 70 years during the most recent analysis period (Table 3). In parallel with these changes, there was a shift towards earlier disease stage with the proportion of patients with stage $0 / 1$ (the earliest stages according to the JIS), rising from $3.4 \%$ between 1966 and 1979 to $53.4 \%$ between 2000 and 2013 (Table 3).

In the Japanese data set, a clear distinction had been recorded between those detected within the formal surveillance programme and the remaining 'unscreened' patients. Those who were screened had an earlier disease stage compared with those who were unscreened. For example, percentages for receiving curative treatment, within the Milan Criteria, tumour sizes $<3 \mathrm{~cm}$, multifocality and vascular invasion were $40.6 \%, 27.7 \%, 22.3 \%$, $62.5 \%$ and $41.7 \%$, respectively, for those who were unscreened compared with $69.1 \%, 71.8 \%, 61.5 \%, 38.4 \%$ and $8.7 \%$, respectively, for screened patients. We therefore applied the previously referenced statistical method to assess the contribution of leadand length-time bias to this cohort. This showed that the difference between the screened and unscreened cohorts decreased from 46.3 to 19.8 months but remained highly significant $(P<0.0001$; Figure $1 \mathrm{~F}$ and Supplementary Figure 2$)$. Median survival in other subgroups are summarised in Table 3.
Role of aetiology and surveillance in HCC survival. Direct comparison between Japan and Hong Kong is complicated by major differences in aetiology, with Japanese patients being predominately HCV related and Hong Kong patients HBV related. Despite this in both aetiologies, patients in Japan clearly survived longer than those in Hong Kong (Supplementary Figures 3a and b) and multivariable analysis (Table 4) showed that tumour-related factors, such as vascular invasion, AFP and tumour size, but not aetiology, accounted for these differences (Supplementary Tables 1 and 2). When disease stage factors are accounted for in a multivariable Cox regression analysis, screening status variable becomes insignificant $(P>0.05)$, indicating that any differences in survival between the two groups (screened and unscreened) is accounted for by disease stage. All univariable analysis is shown in Supplementary Tables 3 and 4 .

\section{DISCUSSION}

The stage of HCC at presentation was the most important factor influencing survival. Patients with early-stage disease are more likely to receive potentially curative therapy and survive longer. When we applied a statistical method that adjusts for lead and length-time bias, significant benefit remained among the screened population in Japan (log-rank test, $P<0.0001$ ). This method has limitations in that it is not specific for HCC but other approaches that make allowance for lead-time bias, using HCC-specific features, have arrived at similar conclusions. Specifically Mourad et al (2014), found the same using a modelling approach and 
A

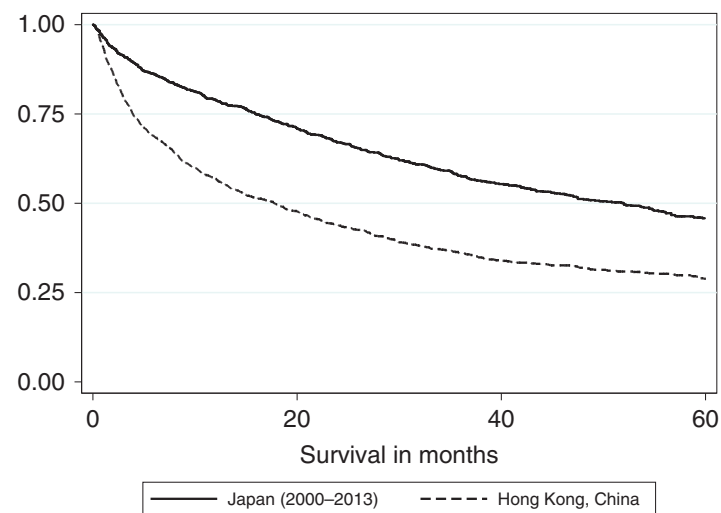

C

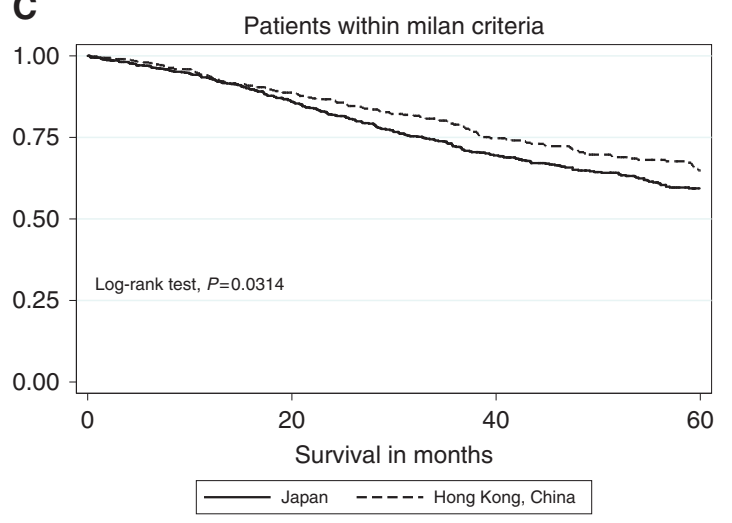

E

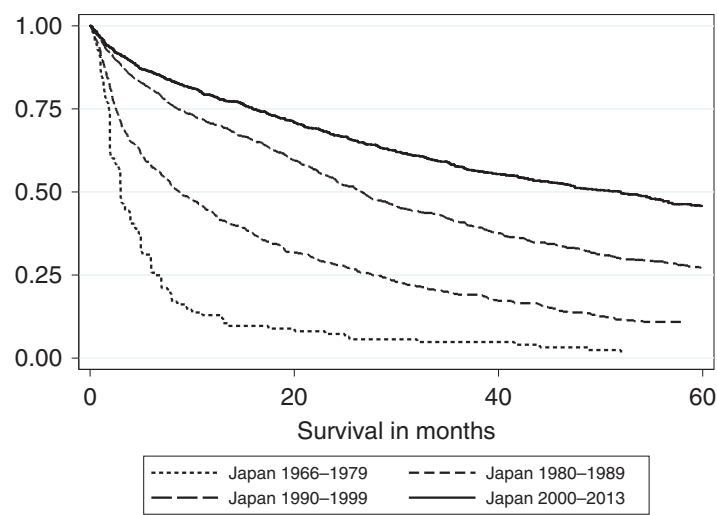

B

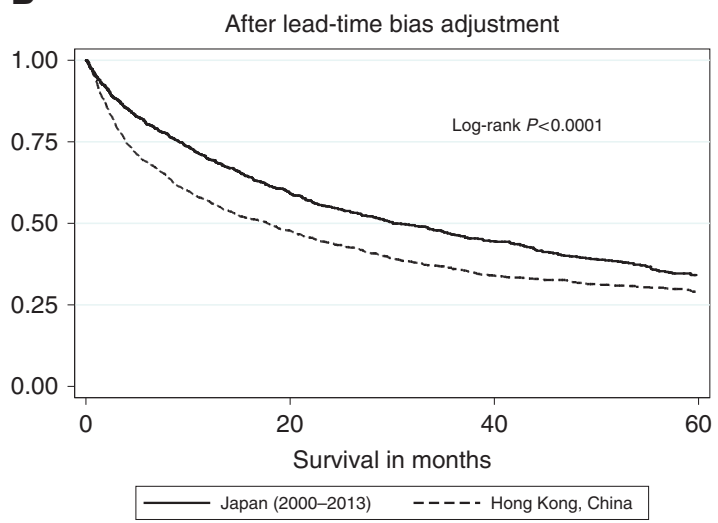

D Patients within milan criteria and Child-Pugh A

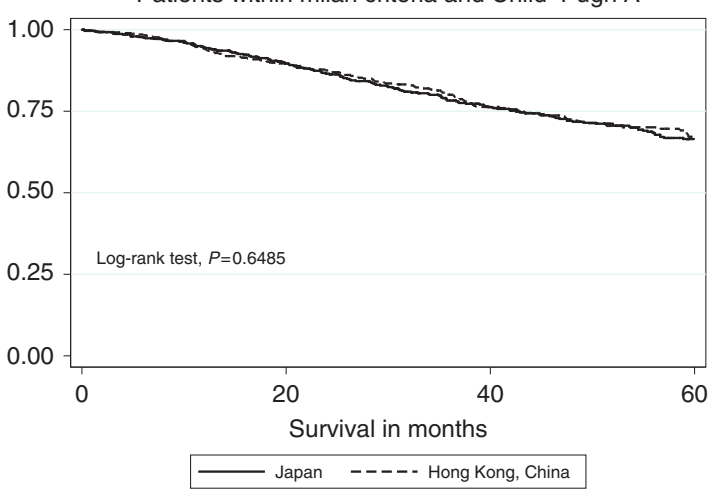

F Japan 2000-2013 (after lead-time ajdustment) vs Hong Kong

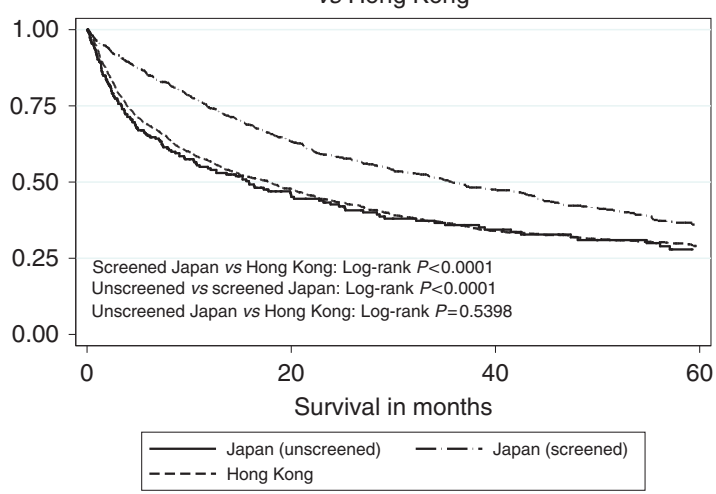

Figure 1. Kaplan-Meier curves showing survival. (A) In the Japanese and Chinese cohorts, (B) in the Japanese and Chinese cohorts after lead-time bias, $(\mathbf{C})$ in Japanese and Chinese patients who were within the Milan criteria, (D) in Japanese and Chinese patients who were within the Milan Criteria and Child-Pugh A, (E) in Japan over the decades (1966-1979, 1980-1989, 1990-1999 and 2000-2013) and (F) survival according to screening status (after lead-time bias adjustment) in the Japanese (and Chinese) cohorts.

\section{Table 2. Percentage of patients with curative treatments, early-stage BCLC and within the Milan Criteria}

\begin{tabular}{|c|c|c|c|c|c|c|}
\hline Cohort & $\%$ screened & $\%$ curative & $\begin{array}{c}\text { \% within Milan } \\
\text { Criteria }\end{array}$ & $\begin{array}{l}\text { \% tumour size } \\
<3 \mathrm{~cm}\end{array}$ & $\%$ multifocal & $\begin{array}{l}\text { \% vascular } \\
\text { invasion }\end{array}$ \\
\hline Japan 1966-1979 & $12.9(n=132)$ & $3.3(n=150)$ & $6.0(n=149)$ & $12.5(n=16)$ & $93.3(n=150)$ & $86.3(n=73)$ \\
\hline Japan 1980-1989 & $53.1(n=375)$ & $16.2(n=476)$ & $20.0(n=476)$ & $30.2(n=291)$ & $75.2(n=476)$ & $62.9(n=464)$ \\
\hline Japan 1990-1999 & $70.1(n=805)$ & $41.9(n=805)$ & $50.1(n=805)$ & $51.4(n=736)$ & $57.9(n=805)$ & $26.6(n=804)$ \\
\hline Japan 2000-2013 & $77.6(n=1172)$ & $62.8^{*}(n=1170)$ & $62.0^{*}(n=1159)$ & $52.8^{*}(n=1164)$ & $43.8^{* *}(n=1165)$ & $16.0 *(n=1163)$ \\
\hline Hong Kong & NA & $44.1^{*}(n=1675)$ & $31.7 *(n=1624)$ & $25.3^{*}(n=1600)$ & $45.4^{\star \star}(n=1675)$ & $26.7^{*}(n=1675)$ \\
\hline
\end{tabular}




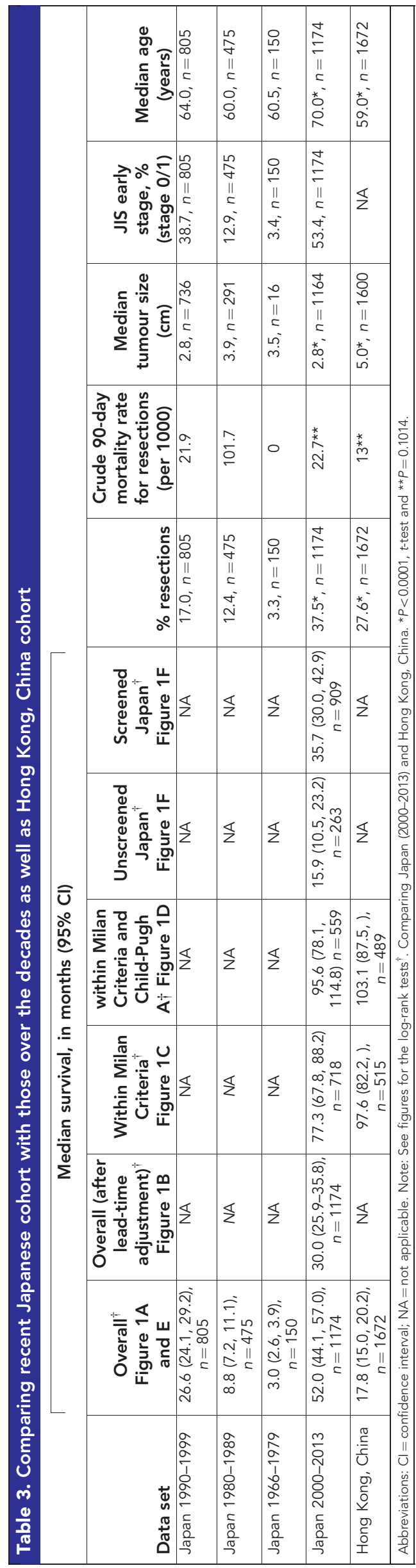

Table 4. Multivariable Cox regression analysis

\begin{tabular}{|c|c|c|c|c|c|c|}
\hline${ }_{-} t$ & $\begin{array}{l}\text { Haz. } \\
\text { ratio }\end{array}$ & s.e & $z$ & $P>z$ & \multicolumn{2}{|c|}{$\begin{array}{l}95 \% \text { Conf. } \\
\text { interval }\end{array}$} \\
\hline \multicolumn{7}{|l|}{ Japan } \\
\hline \multicolumn{7}{|l|}{ Vascular invasion } \\
\hline No & Ref. & & & & & \\
\hline Yes & 2.815 & 0.397 & 7.34 & $<0.0001$ & 2.136 & 3.71 \\
\hline Albumin & 0.91 & 0.008 & -11.16 & $<0.0001$ & 0.895 & 0.925 \\
\hline Log 10 AFP & 1.279 & 0.047 & 6.75 & $<0.0001$ & 1.191 & 1.373 \\
\hline Age & 1.034 & 0.005 & 6.25 & $<0.0001$ & 1.023 & 1.045 \\
\hline \multicolumn{7}{|l|}{ Tumour type } \\
\hline Solitary & Ref. & & & & & \\
\hline Multifocal & 1.605 & 0.153 & 4.97 & $<0.0001$ & 1.332 & 1.935 \\
\hline Tumour size & 1.05 & 0.008 & 6.22 & $<0.0001$ & 1.034 & 1.067 \\
\hline \multirow{2}{*}{\multicolumn{7}{|c|}{ Gender }} \\
\hline & & & & & & \\
\hline $\begin{array}{l}\text { Female } \\
\text { Male }\end{array}$ & $\begin{array}{c}\text { Ref. } \\
1.519\end{array}$ & 0.152 & 4.18 & $<0.0001$ & 1.249 & 1.849 \\
\hline \multicolumn{7}{|c|}{ Hong Kong, China } \\
\hline \multicolumn{7}{|l|}{ Vascular invasion } \\
\hline No & Ref. & & & & & \\
\hline Yes & 2.501 & 0.186 & 12.35 & $<0.0001$ & 2.162 & 2.892 \\
\hline Log 10 bilirubin & 2.625 & 0.263 & 9.65 & $<0.0001$ & 2.158 & 3.194 \\
\hline Tumour size & 1.069 & 0.007 & 9.64 & $<0.0001$ & 1.054 & 1.083 \\
\hline Albumin & 0.949 & 0.006 & -8.76 & $<0.0001$ & 0.938 & 0.96 \\
\hline Log 10 AFP & 1.177 & 0.027 & 7.2 & $<0.0001$ & 1.126 & 1.231 \\
\hline \multicolumn{7}{|l|}{ Tumour type } \\
\hline Solitary & Ref. & & & & & \\
\hline Multifocal & 1.566 & 0.106 & 6.64 & $<0.0001$ & 1.372 & 1.788 \\
\hline Age & 1.008 & 0.003 & 2.62 & 0.009 & 1.002 & 1.013 \\
\hline
\end{tabular}

Cucchetti et al (2014) concluded that even after lead-time bias adjustment, semiannual surveillance maintained a survival benefit over symptomatic diagnosis. The fact that the median age at diagnosis in Japan has not fallen since the surveillance programme was initiated, but rather increased, may offer further evidence that lead-time bias does not account for all the benefit of surveillance. The better survival in Japan is unlikely to be attributable simply to 'better' treatment as, among those Hong Kong patients detected within the Milan Criteria, the latter actually survived longer than the Japanese cohort and by all other measures of survival in earlystage disease according to treatment there were no significant differences.

The progressive improvement in median survival between 1980 (when surveillance was initiated) and 2013 (from $<3$ months to the current figure of $>70$ months) in the Japanese cohort has been replicated across Japan (Ikai et al, 2010). This observation cannot, in itself, be taken as evidence for the benefit of surveillance since there have, over the same period, been major advances in both diagnosis and management. For example, we cannot be entirely confident of the diagnosis of small HCCs in the early stages of the study, before internationally agreed diagnostic criteria were established. However, most small tumours did come to resection and were thus histologically confirmed. Crucially however, whilst in Hong Kong the survival has increased from 3 months (Shiu et al, 1990 ) to 17.8 months, in Japan the improvement (over the same time period) has been to 52 months ( 30 months after adjusting for lead-time bias). Furthermore, the parallel stage-shift to earlier disease (as assessed by the JIS system) supports the contention that survival improvement was, at least in part, attributable to surveillance. In both Hong Kong and Japan, patients with chronic $\mathrm{HCV}$ survived longer than those with HBV, suggesting that the high incidence of $\mathrm{HCV}$ infection might contribute to the better survival in Japan compared with Hong Kong. A direct comparison, however, reveals that within each aetiology, Japanese patients consistently survived longer. Interestingly, in both Japan 
and Hong Kong, irrespective of how the HCC cases were detected, those with HBV had clinical features characteristic of more advanced disease.

However, there are significant limitations to our study. Crucial issues such as cost effectiveness, and any harm inflicted by a surveillance programme such as the consequence of false-positive results, have not been considered. Furthermore, any benefit of surveillance suggested here is not necessarily transferable to a Western setting. Obesity is increasingly recognised as an aetiological factor for HCC development in the West and this will decrease the sensitivity of US examination, whereas US is likely to be a more effective surveillance tool in the slimmer Japanese population (Zaman, 2013). In Japan, patients at risk are a wellinformed population committed to surveillance and this may not be the case in the West where compliance may be poor, especially among those with alcoholic cirrhosis. Furthermore, only patients in whom the presence of a risk factor for HCC is known (e.g., chronic viral hepatitis) will enter a surveillance programme. In Hong Kong, HCC was often the first manifestation of chronic hepatitis B infection, whereas in Japan the population had already been offered screening for the presence of chronic HBV or HCV. There is abundant evidence from the United States that management strategies developed and implemented in specialist centres are not always replicated in the primary care setting and that the overall percentage of patients with cirrhosis actually undergoing effective surveillance is very low (El-Serag and Davila, 2010; DaltonFitzgerald et al, 2014; Joshi et al, 2014). The multiple barriers that inhibit translation of the potential benefits of surveillance into an effective program at the population level have been clearly described by Singal and El-Serag (2015).

Although a prospective randomised controlled trial (RCT) to assess the impact of surveillance would be ideal, it is now recognised that this approach is not practical (Poustchi et al, 2011; McCaughan, 2013; Kansagara et al, 2014; Singal et al, 2014; Sherman, 2014a, b); all other, non-RCT-based approaches have significant limitations. Nonetheless, in the absence of an RCT, our data when combined with the time trends shown here, and reports from the whole of Japan (Toyoda et al, 2006a) and other parts of Asia (Yeh et al, 2014), lend strong support for the beneficial impact of surveillance on HCC mortality.

\section{ACKNOWLEDGEMENTS}

The authors gratefully acknowledge the help of all those who contributed to the collection of the data sets used in this study. From Hong Kong, Ms Jane Koh had a major role in data collection and tabulation. We are also indebted to Stephen Duffy, Professor of Cancer Screening at the Wolfson Institute of Preventive Medicine, University of London, who gave us access to the statistical methodology that permitted correction for lead and length-time bias. Statistical analysis was supported in part by a grant from Liverpool Health Partners (JXR10979).

\section{CONFLICT OF INTEREST}

The authors declare no conflict of interest.

\section{REFERENCES}

Bruix J, Sherman M (2011) Management of hepatocellular carcinoma: an update. Hepatology 53: 1020-1022.

Chen CH, Su WW, Yang SS, Chang TT, Cheng KS, Lin HH, Wu SS, Lee CM, Changchien CS, Chen CJ, Sheu JC, Chen DS, Lu SN (2006) Long-term trends and geographic variations in the survival of patients with hepatocellular carcinoma: analysis of 11312 patients in Taiwan. J Gastroenterol Hepatol 21: 1561-1566.

Cucchetti A, Trevisani F, Pecorelli A, Erroi V, Farinati F, Ciccarese F, Rapaccini GL, Di Marco M, Caturelli E, Giannini EG (2014) Estimation of lead-time bias and its impact on the outcome of surveillance for the early diagnosis of hepatocellular carcinoma. J Hepatol 61: 333-341.

Dalton-Fitzgerald E, Tiro J, Kandunoori P, Halm EA, Yopp A, Singal AG (2014) Practice patterns and attitudes of primary care providers and barriers to surveillance of hepatocellular carcinoma in patients with cirrhosis. Clin Gastroenterol Hepatol 13: 791-8.e1.

Duffy SW, Nagtegaal ID, Wallis M, Cafferty FH, Houssami N, Warwick J, Allgood PC, Kearins O, Tappenden N, O'Sullivan E (2008) Correcting for lead time and length bias in estimating the effect of screen detection on cancer survival. Am J Epidemiol 168: 98-104.

El-Serag HB, Davila JA (2010) Surveillance for hepatocellular carcinoma: in whom and how? Therap Adv Gastroenterol 4(1): 5-10.

For Research EOLiver, EAFTSOT (2012) EASL-EORTC Clinical Practice Guidelines: management of hepatocellular carcinoma. J Hepatol 56: 908-943.

Hsu C, Shen YC, Cheng CC, Hu FC, Cheng AL (2010) Geographic difference in survival outcome for advanced hepatocellular carcinoma: implications on future clinical trial design. Contemp Clin Trials 31: 55-61.

Ikai I, Kudo M, Arii S, Omata M, Kojiro M, Sakamoto M, Takayasu K, Hayashi N, Makuuchi M, Matsuyama Y (2010) Report of the 18th follow-up survey of primary liver cancer in Japan. Hepatol Res 40: 1043-1059.

Joshi K, Mendler M, Gish R, Loomba R, Kuo A, Patton H, Kono Y (2014) Hepatocellular carcinoma surveillance: a national survey of current practices in the USA. Dig Dis Sci 59(12): 3073-3077.

Kansagara D, Papak J, Pasha AS, O’Neil M, Freeman M, Relevo R, Quiñones A, Motu'Apuaka M, Jou JH (2014) Screening for hepatocellular carcinoma in chronic liver disease: a systematic review. Ann Intern Med 161: 261-269.

Kudo M, Chung H, Osaki Y (2003) Prognostic staging system for hepatocellular carcinoma (CLIP score): its value and limitations, and a proposal for a new staging system, the Japan Integrated Staging Score (JIS score). J Gastroenterol 38: 207-215.

Kudo M, Izumi N, Sakamoto M, Matsuyama Y, Ichida T, Nakashima O, Matsui O, Ku Y, Kokudo N, Makuuchi M, Liver Cancer Study Group of Japan (2016) Survival Analysis over 28 Years of 173378 Patients with Hepatocellular Carcinoma in Japan. Liver Cancer 5: 190-197.

Llovet JM (2005) Updated treatment approach to hepatocellular carcinoma. J Gastroenterol 40: 225-235.

Mazzaferro V, Regalia E, Doci R, Andreola S, Pulvirenti A, Bozzetti F, Montalto F, Ammatuna M, Morabito A, Gennari L (1996) Liver transplantation for the treatment of small hepatocellular carcinomas in patients with cirrhosis. $N$ Engl J Med 334: 693-700.

McCaughan GW (2013) Early hepatocellular carcinoma-Is there such a thing as too early? J Hepatol 58: 210-211.

Mourad A, Deuffic-Burban S, Ganne-Carrié N, Renaut-Vantroys T, Rosa I, Bouvier AM, Launoy G, Cattan S, Louvet A, Dharancy S (2014) Hepatocellular carcinoma screening in patients with compensated hepatitis $\mathrm{C}$ virus (HCV)-related cirrhosis aware of their HCV status improves survival: A modeling approach. Hepatology 59: 1471-1481.

NCI. National Cancer Institute - Liver (Hepatocellular) Cancer Screening $(P D Q \AA)$ [Online]. Available at http://www.cancer.gov/cancertopics/pdq/ screening/hepatocellular/HealthProfessional.

Omata M, Lesmana LA, Tateishi R, Chen P-J, Lin S-M, Yoshida H, Kudo M, Lee JM, Choi BI, Poon RT (2010) Asian Pacific Association for the Study of the Liver consensus recommendations on hepatocellular carcinoma. Hepatol Int 4: 439-474.

Parkin DM, Bray F, Ferlay J, Pisani P (2005) Global cancer statistics, 2002. CA Cancer J Clin 55: 74-108.

Poustchi H, Farrell GC, Strasser SI, Lee AU, McCaughan GW, George J (2011) Feasibility of conducting a randomized control trial for liver cancer screening: Is a randomized controlled trial for liver cancer screening feasible or still needed? Hepatology 54: 1998-2004.

Sherman M (2014a) Screening for liver cancer: another piece of the puzzle? Hepatology 59: 1673-1675.

Sherman M (2014b) Surveillance for hepatocellular carcinoma. Best Pract Res Clin Gastroenterol 28: 783-793.

Shiu W, Dewar G, Leung N, Leung WT, Chan M, Tao M, Lui C, Chan CL, Lau WY, Metreweli C, Li AKC (1990) Hepatocellular carcinoma in Hong Kong: clinical study on 340 cases. Oncology 47: 241-245. 
Singal AG, El-Serag HB (2015) Hepatocellular Carcinoma From Epidemiology To Prevention: Translating Knowledge Into Practice. Clin Gastroenterol Hepatol 13: 2140-2151.

Singal AG, Pillai A, Tiro J (2014) Early detection, curative treatment, and survival rates for hepatocellular carcinoma surveillance in patients with cirrhosis: a meta-analysis. PLoS Med 11: e1001624.

Song P, Tobe RG, Inagaki Y, Kokudo N, Hasegawa K, Sugawara Y, Tang W (2012) The management of hepatocellular carcinoma around the world: a comparison of guidelines from 2001 to 2011. Liver Int 32: 1053-1063.

The Japan Society of Hepatology (2010a) Chapter 2: diagnosis and surveillance. Hepatol Res 40: 16-47.

The Japan Society of Hepatology (2010b) Surveillance algorithm and diagnosis algorithm for hepatocellular carcinoma. Hepatol Res 40: 6-7.

Toyoda H, Kumada T, Kiriyama S, Sone Y, Tanikawa M, Hisanaga Y, Yamaguchi A, Isogai M, Kaneoka Y, Washizu J (2006a) Impact of surveillance on survival of patients with initial hepatocellular carcinoma: a study from Japan. Clin Gastroenterol Hepatol 4: 1170-1176.

Toyoda H, Kumada T, Osaki Y, Oka H, Urano F, Kudo M, Matsunaga T (2006b) Staging hepatocellular carcinoma by a novel scoring system (BALAD score) based on serum markers. Clin Gastroenterol Hepatol 4: 1528-1536.
Yeh YP, Hu TH, Cho PY, Chen HH, Yen AMF, Chen SLS, Chiu SYH, Fann JCY, Su WW, Fang YJ (2014) Evaluation of abdominal ultrasonography mass screening for hepatocellular carcinoma in Taiwan. Hepatology 59: 1840-1849.

Zaman A (2013) Diabetes and Obesity Greatly Contribute to Hepatocellular Carcinoma:reviewing Welzel TM et al Am J Gastroenterol 2013 Aug. [Online]. Journal Watch. Available at http://www.jwatch.org/na32053/ 2013/09/11/diabetes-and-obesity-greatly-contribute-hepatocellular (accessed 11 September 2013).

Zhang B-H, Yang B-H, Tang Z-Y (2004) Randomized controlled trial of screening for hepatocellular carcinoma. J Cancer Res Clin Oncol 130: 417-422.

(c) (i) This work is licensed under the Creative Commons Attribution 4.0 International License. To view a copy of this license, visit http://creativecommons.org/licenses/ by/4.0/

(C) The Author(s) named above 2017

Supplementary Information accompanies this paper on British Journal of Cancer website (http://www.nature.com/bjc) 